\title{
Can Tax Compliance Research Profit from Biology?
}

\author{
by Benno Torgler ${ }^{*}$
}

\begin{abstract}
Historically, tax compliance has been a highly interdisciplinary avenue of research to which economics, psychology, law, sociology, history, political science, and accountancy have made valuable contributions. It is less well understood, however, whether we can glean useful insights into tax compliance by moving beyond the social sciences. In particular, the literature pays little attention to the relevance of biology. This paper attempts to remedy this shortcoming by examining the potential opportunities and limitations of introducing biological concepts into tax compliance research.
\end{abstract}

Keywords: tax compliance, tax morale, tax evasion, biology, genetics, neurobiology, demography, human drives, agent-based modelling

JEL Classification: H26, B40, B52, C63, D03, Z19

\footnotetext{
* QuBE, Queensland Behavioural Economics Group, The School of Economics and Finance, Queensland University of Technology, Gardens Point, 2 George St., Brisbane, QLD 4001, Australia, email: benno.torgler@qut.edu.au; CREMA - Center for Research in Economics, Management and the Arts, Gellertstrasse 18, CH-4052 Basel, Switzerland; and EBS Business School, EBS Universität für Wirtschaft und Recht, Rheingaustraße 1, 65375 Oestrich Winkel. I would like to express my gratitude to the participants of the Vienna workshop on Research Methods in Tax Research and to Aloys Prinz for sharing research that provided valuable insights into the current state of agent-based modeling in the tax compliance literature. This work was supported by the Australian Research Council (ARC) Future Fellowship FT110100463. For helpful comments and suggestions, thanks are due to Alison Macintyre.
} 
One more hominid joining the Java men and Neanderthals in extinction was the intellectual Renaissance man, the scholar with a command of many disciplines. If human beings are to learn more about how the world works and, better, to direct their collective understanding toward the long-term service of humanity, specialization is necessary. At the same time, because few significant human problems today lie strictly within the boundaries of current disciplines, much more should be done to encourage interdisciplinary scholarship. A disciplinary scholar does not need to be blind to other areas and should not consider disciplinary boundaries to be forever fixed. Rather, they should be viewed as eternally flexible and porous, and those who choose to tackle problems that cross the boundaries of the moment should not be punished, as they often are in academia today. The conservatism that was useful in the past is a luxury that society can no longer afford. Society also can no longer afford the split between the humanities and the sciences (the "two cultures" of physicist C. P. Snow) or the marginalization of philosophy.

Paul R. Ehrlich (2000). Human Natures, p. 326

\section{INTRODUCTION}

Tax compliance has always been a field to which social scientists from economics, psychology, law, sociology, history, political science, and accountancy have made valuable contributions. Hence, researchers working in the area understand well that the relationship between the sciences can be one of mutual benefit, motivated by the multifaceted issues surrounding the topic, the evidence collected, and the substantial challenges related to data problems. Alm (1998), for instance, a major influence in tax compliance over the last three decades, offers the following testament to the necessity of such openness:

These findings suggest that it is unlikely that a single unifying theory of tax compliance can ever be devised, one that incorporates the incredible variation in individual behavior exhibited by the many analyzes of taxpayer compliance, one that explains the behaviour of all individuals at all times, or even one that explains the actions of the same person at all times. Perhaps our research should still be devoted to the pursuit of such a holy grail. More importantly, however, our research needs to recognize that a 'theory' of taxpayer compliance must really consist of a 'full house' of theories, each explaining the behaviour of different individuals at different times. Any tax administration must also recognize that it must address this 'full house'" of behaviors in devising policies to ensure compliance. (pp. 48-49)

In later work, Alm et al.'s (2010) aim is to bring researchers from different disciplines together to provide a more complete understanding of individual and group tax 
compliance decision making. The cross-disciplinarity is well exemplified in Kirchler (2007) and Pickhardt and Prinz 2014).

Because the intersections at which disciplines meet offer unique opportunities for innovation, their exploration is important beyond academia. Such extension is amply illustrated by Johansson's (2004) personality studies, which show how intersections of ideas, concepts, and cultures can fruitfully enhance creativity and innovation. Wilson (1998), in his Consilience: The Unity of Knowledge, stresses that the "greatest enterprise of the mind has always been and always will be the attempted linkage of the sciences and humanities" (p. 8), whereas Haldane (2009) remarked during a 1952 lecture that "science advances both when a new question is asked and when it is answered" (p. 199). Given that different fields ask different questions—or similar questions using different methods or from different perspectives-it is worth reflecting on whether hard sciences such as biology can contribute to research contexts like tax compliance that to date have been primarily social science enterprises. This article thus investigates whether important insights into tax compliance can be gleaned by moving beyond social sciences with a specific focus on biology. Obviously, such an initial attempt can only scratch the surface and is subject to pitfalls; especially, given this author's limited expertise and literacy in the biological field. The discussion, therefore, is more illustrative than comprehensive.

One possible link between the fields of tax compliance and biology is that the former can be seen as a subfield of the literature on cooperation, an area in which biology has been relatively influential. Biology has, for example, had a strong impact on such prominent economists as Herbert Gintis or Samuel Bowles (see, e.g., Bowles and Gintis 2011), Ken Binmore, and Ernst Fehr. It is therefore somewhat puzzling that while the cooperation literature has been driven by attempts to understand how cooperation evolves, the tax compliance literature has not been so dominated by biological considerations. This omission is especially puzzling given that taxation lies at the core of a civilized society and that the social contract between taxpayer and government has survived over time and through many different civilizations (see, e.g., Webber and Wildavsky 1986). The next section, therefore, goes beyond taxation and cooperation to explore the relation between economics and biology.

At this point, it is also valid to ask why it is worthwhile to investigate the interaction between economics and biology rather than physics. One reason for this choice is that, because a system's emergent properties cannot be understood by 
simply looking at its components, the emergent phenomena in the economic or social environment in which taxation is embedded are less observable in a physical world than in a biological one (Helbing 2012). For example, the fact that social interactions at the horizontal level (e.g., Frey and Torgler 2007, Traxler 2010) or vertical level (e.g., Braithwaite 2002, Kirchler 2007, Torgler 2003, 2007) are crucial for understanding tax compliance makes the biological approach an attractive avenue of inquiry.

\section{When ECONOMICS MEETS BiOLOGY}

Social science has constantly come under attack from researchers in the hard sciences, a criticism exemplified by the following comment from Feynman (1999):

Because of the success of science, there is, I think, a kind of pseudoscience. Social science is an example of a science which is not a science: they don't do [things] scientifically, they follow the forms - or you gather data, you do so-and-so and so forth but they don't get any laws, they haven't found out anything. They haven't got anywhere yet - maybe someday they will, but it's not very well developed, but what happens is on an even more mundane level. (p. 22)

Wilson (1998), on the other hand, points out that social science's striving to achieve predictive capacity has not been very successful without a linkage to the natural sciences. He sees social science as "snarled by disutility and a failure of vision [... and] shackled by tribal loyalty," further suggesting that "never-I do not think that too strong a word-have social scientists been able to embed their narratives in the physical realities of human biology and psychology, even though it is surely there and not some astral plane from which culture has arisen" (pp. 198-199). A book by Mirowski (1989) even has an entire chapter entitled the "Ironies of Physics Envy."

The dream of unifying social sciences with natural sciences, however, is not a new one. For example, the "father of sociology," August Comte, hoped that a natural science approach would help unravel the puzzles of social systems, which inspired him to develop social physics (Helbing 2012). Many other eminent scientists have also been attracted by the goal of bringing rigor into social science (e.g., Simon 1996a, Samuelson 2004). In Simon's (1996a) words: “I believe (my third creation myth) that what brought me to the social sciences was the urge to supply rigor to a body of phenomena that sorely needed it. Physics was already too far long (I thought) for genuine adventure. The social sciences offered a field of virgin snow on which 
one could imprint a fresh form" (p. 366). Samuelson (2004) criticizes the lack of rigor when, in 1932, he first began to study economics at the University of Chicago Midway:

[Back then] economics was literary economics. A few original spirits-such as Harold Hotelling, Ragnar Frisch, and R. G. D. Allen — used mathematical symbols; but, if their experiences were like my early ones, learned journals rationed pretty severely acceptance of anything involving the calculus. Such esoteric animals as matrices were never seen in the social science zoos. At most a few chaste determinants were admitted to our Augean stables. Do I seem to be describing Eden, a paradise to which many would like to return in revulsion against the symbolic pus-pimples that disfigure not only the pages of Econometrica but also the Economic Journal and the American Economic Review? Don't believe it. Like Tobacco Road, the old economics was strewn with rusty monstrosities of logic inherited from the past, its soil generated few stalks of vigorous new science, and the correspondence between the terrain of the real world and the maps of the economics textbook and treatises was neither smooth nor even one-to-one. (p. 49)

Karier (2010), in contrast, in his Intellectual Capital: Forty Years of the Nobel Prize in Economics, points out that almost all the Nobelists had a strong mathematical background but criticizes how "[e]conomists find a high degree of satisfaction from converting familiar ideas into mathematics and an even greater sense of accomplishment from proving mathematically what anyone else might recognize as common sense [... suggesting that] economic models may become little more than castles in the sky" (pp. 6-7). He therefore gives some tough advice:

Stop trying to emulate the Nobel physical and natural sciences. There was a time when it was important to minimize and maximize functions to test whether this particular approach could solve economic problems. For the most part, it did not. Unlike physical or natural scientists, economists cannot prove their ideas or theories on a blackboard, or, for the most part, in a laboratory. For whatever reasons, applying the tools of physics did not provide a deep understanding of real economic behaviour. The age of Samuelson, Solow, Hicks, and Debreu was certainly a golden age for mathematical economists, but that approach evidently has run its course. Good economic ideas do not have to be proven mathematically in a journal article. ${ }^{1}$ (p. 303)

Obviously, this latter is a radical statement: laboratory and field experiments have provided substantial insights into human nature, as is evident, for example, in the area of behavioral economics (e.g., decision making under risk and intertemporal choices).

\footnotetext{
${ }^{1}$ For a more extensive discussion on the role of mathematics and the level of technique, see Torgler and Piatti (2012, 2013) and Samuelson (1952).
} 
Yet even though mathematics has been so dominant among Nobel laureates, a more detailed examination is needed to understand how far, for which questions, and under what sort of conditions mathematics should be used. Samuelson (1952), for instance, while admitting that he "hold[s] no brief for economic theory [thinking that] the pendulum will always swing between interest in concrete description and attempts to construct abstract summaries of experience, with one decade and tradition giving more emphasis to the one process and another time and place giving emphasis to the other," also believes that "when the pendulum is swinging in favor of the theory, there will be kind of a Gresham's law operating whereby the more convenient deductive method will displace the less convenient" (p. 64).

It is also obvious that Wilson's criticism that social scientists have been unable to "embed their narratives" in biological and psychological reality has become outdated. Social scientists researching decision making have developed a natural interest in looking at biological microfoundations and the field has attracted the attention of many bright and leading minds in economics. Arthur J. Robson, for example, has made important contributions on the biological basis of economics, posting the following commentary on his homepage:

I have been persuaded for about 20 years by the idea that a strong light can be shed on modern human economic behavior by considering its biological and anthropological basis. I wanted to otherwise stick to the usual theoretical methodology in carrying out this program. Research on this topic definitely wasn't short-run career optimizing, but it has been, and still is, tremendous fun to do something new. It is also encouraging that recently there has been an increase in acceptance of this approach from the discipline at large. (http://www.sfu.ca/ robson/)

His publication record in such leading economic journals as Econometrica and American Economic Review reflects his success ${ }^{2}$ and may encourage (or may already have encouraged) many additional researchers young and old to tackle that field.

Economists long ago recognized the parallel relationship between economics and biology, which Hirshleifer (1977) describes as follows: "The fundamental organizing concepts of the dominant analytical structures employed in economics and in

\footnotetext{
${ }^{2}$ The Cheap Talk blog reports the following interesting event: "At that conference, Balazs Szentes thanked the organizers, Arthur and Gary Becker, with a speech like this (paraphrasing from memory): 'Everyone thinks Becker is such a great pioneer but really he is so risk-averse. He invented like 20 fields just hoping that one or two of them would take off. Arthur on the other hand is the real hero to economics. He was doing perfectly fine writing about normal theory and then he completely and permanently screwed up his career to pursue this biology and economics stuff. So thank you."” (http://cheaptalk.org/2012/07/16/guest-blogger-arthur-robson/).
} 
sociobiology are strikingly parallel” (p. 2). Likewise, several economics papers on biology refer in their introduction to Malthus's influence on Darwin and Wallace (e.g., Hirshleifer 1977, Tullock 1978, Samuelson 1985, Robson 2001). Less well known, however, is the role that Benjamin Franklin played in Malthus's formulation of his ideas about human population (Hirshleifer 1977, p. 4). In fact, during the 19th century, demography was part of political economy (Samuelson 1985), and economists often quote Alfred Marshall's (1890) claim in his Principles of Economics that "economics has no near kinship with any physical science. It is a branch of biology broadly interpreted" (Hirshleifer 1977, p. 1). Similarly, Niehans (1990), discussing Marshall in his tour de force, A History of Economic Theory, stresses that " $[\mathrm{t}]$ here are also, in keeping with the social Darwinism of the time, many biological analogies of firms with the organisms competing for survival and Herbert Spencer's influence is acknowledged in the preface. At the same time, Marshall's emphasis on historical evolution puts him close to the historical school, and Hegel's philosophy of history is mentioned as the other principal influence on his view" (p. 239). This "hankering" for a biological approach to political economy that emerged with Marshall, however, is criticized by Samuelson (1985), who believes that the host of writers in his wake have produced only a "disappointing paucity [...] of fruitful findings or insights" (p. 348). Yet bioeconomics can be dated back at least to Linnaeus who, in the 18th century, apparently coined the term "the economy of nature" (Corming 2009). A key problem with biology in general, however, is that it, unlike physics, is not well represented by mathematical models, a problem that also plagues the exploration of socioeconomic systems by economics or more broadly, by social sciences (Helbing 2012). In fact, statistical noise in social sciences is comparable to a foggy condition in the real world (Helbing 2012, p. 12).

At certain points in time, however, the two disciplines of biology and economics have been disconnected; for example, during the 1930s, when scholars became impatient with how the evolutionary idea was being used. In Schumpeter's (2012) words, "the evolutionary idea is now discredited in our field, especially with historians and ethnologists, for still another reason. To the reproach of unscientific and extra-scientific mysticism that now surrounds the 'evolutionary' ideas is added that of dilettantism. With all the hasty generalizations in which the word 'evolution' plays a part, many of us have lost patience” (pp. xxx). Yet Schumpeter's dynamic view of the economy has had a major influence on evolutionary economics and 
inspired evolutionary simulations that were impossible in his day (for an excellent overview, see Zak and Denzau 2001 and also Corning 2005 on bioeconomics). Moreover, the connection between these neighbor disciplines is always relatively close and cannot resist the gravitational forces of such concepts as competition, cooperation, adaptation, or survival. For example, Alfred Lotka's influential Elements of Physical Biology has always had a vibrant presence in the social sciences, as testified to by Henry Schultz's recommending it to his students as important reading (see, e.g., Simon 1996a, p. 52, Samuelson 2004, p. 54).

In fact, the emergence of sociobiology led to a renaissance of research contributions among economists aimed at providing a better understanding of human nature by outsourcing the economics toolkit (see, e.g., Becker 1974, Hirshleifer 1977, Frech 1978, Tullock 1978). As Samuelson commented, once the genie is out of the bottle not even the reproductive value of Sir Ronald Fisher is safe (Samuelson 1980, 1977, 1978a, 1978b). The attack, however, does not end there:

[A] fresh analysis of some of the misleading and romantic notions about maximizing that are loosely used in all-too much of biological writings on evolution. Most of the lines that follow were written in the last fortnight, partly for a different purpose, mainly to substitute some light for heat in the polemics that have emerged over the proponents and critics of something called Sociobiology. I venture to hope that coals designed for export from Newcastle may merit a measure of honor in their home county. (Samuelson 1978, p. 173)

Researchers in evolutionary economics-including Thorstein Veblen, Kenneth Boulding, Geoffrey Hodgson, Michael Rothschild, and Richard R. Nelson and Sidney Winter (in their influential An Evolutionary Theory of Economic Change)- have also stayed in close connection with biology. A large number of such researchers have also been influenced by the seminal work of Alchian (1950), who posits that profit maximization is not meaningful in cases of uncertainty, which arise from imperfect foresight and human inability to solve complex problems (p. 212). He also argues that the mark of success or survival is positive profits rather than maximum profits $(p$. 213), meaning that a firm's aggregate position relative to actual competitors (i.e., relative superiority) can be crucial to its prosperity. Yet because achieving this position may be the result of fortuitous circumstances rather than proper motivation, sheer chance can also be an element of success - as can ability to adapt to the environment, which requires neither individual rationality nor individual motivation 
and foresight (p. 214). The environment in turn can adapt to survivors without motivation.

An economist, therefore, can derive conclusions by comparing the types of behavior that would have a higher probability of viability or adoption (Alchian 1950, p. 216). Doing so emphasizes two forms of conscious adaptive behavior: The first is the copying of observable success by others (imitative rules) driven by the absence of an identifiable criterion for decision making, variability in the environment, a multiplicity of factors, uncertainty in all these factors and outcomes, awareness of relative superiority, and unavailability of a trial-and-error process that converges to an optimum (pp. 218-220). Such imitation reduces the need to make decisions and conscious innovations. The second is the conversion of trial and error into a matter of survival or death rather than a mechanism for convergence to the optimum: "Success is discovered by the economic system through a blanketing shotgun process, not by the individual through a converging search" (p. 219). Hence, imperfect imitation provides opportunity for innovation. As Alchian (1950) puts it, "all the preceding arguments leave the individual economic participant with imitative, venturesome, innovative, trial-and-error adaptive behavior. Most conventional economic tools and concepts are still useful, although in a vastly different analytical framework- one which is closely akin to the theory of biological evolution. The economic counterparts of genetic heredity, mutations, and natural selection are [thus] imitation, innovation, and positive profits" (pp. 219-220).

Obviously, the literature on evolutionary economics is too extensive to cover here, but Corning (2009) does provide a valuable overview that includes links to important contributions. It also, however, raises an important criticism; namely, that evolutionary economics is too focused on explaining how economies grow, change, or decline without taking into account how they meet or fail basic needs (p. 232). Environmental (or ecological) economics has been strongly influenced by biology (or more precisely) ecology. Moreover, particularly relevant is Herbert Simon's pioneering work on the architecture of complexity and the linkages between physical, biological, and social hierarchies (e.g., Simon 1996b). Simon (1996b), for example, stresses that physical and biological hierarchies are localized spatially while social hierarchies are focused on who interacts with whom. He also suggests that hierarchies and processes akin to natural selection appear in problem solving, a process that involves selective trial and error (p. 194). Such selectivity is derived from various 
rules of thumb or heuristics that suggest which parts should be targeted first based on feedback information from the environment. In this context, a lack of progress signals the need to abandon research attempts.

\section{Biology ANd TAX Compliance}

According to Mayr (2004), biology can be classified into two fields: mechanistic (functional) biology, which deals with the physiology of a living organism's activities as explained by chemistry and physics, and historical biology, which provides an explanation of the living world involving the dimension of historical time (e.g., evolutionary biology). The first field asks the how question, whereas the second more frequently probes the why. Hence, testing historical narratives and comparing different evidence - processes common in social sciences - are important methods in historical biology and comparative analysis is a powerful methodological tool just as in the social sciences. Natural laws, however, play a lesser role in biological theory formation because of the greater role of chance and randomness (Mayr 2004). The probabilistic nature of generalizations in evolutionary biology also prevent the use of Popper's falsifiability test: rather, despite the existence of regularities in biology, theories are based on concepts. Likewise, in social sciences, it is concepts rather than laws that are documented, although the probabilistic nature of generalizations is seen as somewhat less problematic when exploring human nature and society. Social science has therefore been attracted to and influenced by historical biology. Nevertheless, knowledge interference through falsification is dominant in social science, and it remains to be seen to what extent new technologies in the area of neurobiology can provide social sciences with functional tools for understanding human nature. More generally, what biology and social sciences have in common is that most important invariants are not of quantitative but of qualitative structure ${ }^{3}$ and systems change adaptively over time (Simon 1990).

\section{THEORETICAL FRAMEWORK}

Although the usual simplicity of tax compliance models is not altogether bad, the interaction between the tax administration and the taxpayers is often modeled in one

\footnotetext{
${ }^{3}$ Simon (1990) provides a useful example of the germ theory: "If you observe pathology, look for a microorganism - it might be causing the symptoms" (p. 2).
} 
of two ways: (i) a standard principal-agent framework in which the tax administration announces and commits to an audit process before taxpayers file returns or (ii) a standard game-theoretic concept of sequential equilibrium in which administration does not commit to its audit rule ex ante but decides on it after returns are filed (Andreoni et al. 1998). Yet, as Andreoni et al. (1998) acknowledge, such models have substantial limitations, ranging from a poor description of the real-world tax system to limited predictive power and questionable or restrictive assumptions. Moreover, as Haldane (2008) has suggested, "no scientific theory is worth anything unless it enables us to predict something which is actually going on. Until that is done, theories are a mere game with words, and not such a good game as poetry" (p. 58).

The question therefore arises of how improvements might be achieved, with one possibility being a more organic approach. Biology, for example, might help us better integrate the importance of the geographic and historical space embedded in time and improve our understanding of how information, communication, and feedback mechanisms work in the horizontal and vertical interrelations between the key decision makers (e.g., taxpayers; tax administration; local, regional, and national governance; and tax practitioners). Such a perspective, however, raises yet another question: are horizontal interactions more rapid and intense than vertical? In particular, because interactions within biological units are more rapid and intensive than those between units (Simon 1996b), it is important to observe who interacts with whom and how intensive these interactions are in a habitual network of communication. It may be worth exploring, for instance, whether the process of tax compliance can be modelled in a manner similar to a living system (Miller 1978). Similarly, accepting that this approach suggests a dynamic framework, what precisely does dynamic mean? As Samuelson (1983) wittily points out, "we damn another man's theory by terming it static, and advertise our own by calling it dynamic. Examples of this are too plentiful to require citation" (p. 311). Moreover, modelling implies trade-offs: as succinctly stated by atmospheric scientist John A. Dutton, "it is not possible simultaneously to maximize generality, realism, and precision" (cited in Slingerland and Kump 2011, p. 3).

As a result of such considerations, there is a trend in biology of reconsidering the theoretical toolset. Cazalis (2013), for instance, explains that an adequate description of an individual defined as a biological organism, from the most basic form to a human being, requires a new language that expresses (among other things) spatial 
movements, interactions with the environment, and self-regulation. Kitto and Kortschak (2013) further point out that biological systems are inherently contextual, meaning that entities can exhibit different responses to the same stimulus if it occurs within a different context (p. 97). To encompass these issues, models must be extended well beyond the Newtonian paradigm dominant in economics, a paradigm originally developed to understand phenomena from the physical world. As Kitto and Kortschak (2013) note, standard reductive approaches to mathematical modeling fail in systems that exhibit high end complexity, but a class of mathematics already exists that allows us to model contextuality (i.e., quantum theory).

In the area of tax compliance, context is important (Spicer 1990, McGee 1996, Torgler 2001); for example, willingness to pay depends on whether taxes go to finance a dictator's war machine (McGee 1996) or support a highly democratic and accountable environment. In fact, Hernando de Soto (2000) demonstrates a need to break Peruvian law in order to create a new and perfectly legal small business in Lima. The emergence or survival of a firm is likewise context specific: the parameters of the problem differ for each firm and thus require proper modeling of the firmenvironment relation. In this scenario, time and energy are limited for all involved parties, whether individual taxpayer or firm, tax administration, or tax practitioner, so they searches for specific strategies and tactics that satisfy their needs, demands, and restrictions. There is thus a close interdependency, cooperation, and symbiosis between these actors as they adapt over time that resembles certain universal bioeconomic principles (Corning 2005).

Contextual elements are also important methodologically: for example, in surveys, the dominant tool in the tax compliance literature, individuals' tax attitudes and values are not static (Torgler 2001). In fact, many economists are reluctant to use survey data, suspecting that the explicitly expressed attitudes differ from those actually held, which makes attitudes very difficult to model in standard mathematical frameworks. It is also worth noting, however, that the differences between physics and biology are deteriorating as physics transitions from a state perspective to the process perspective dominant in biology (Matsuno 2013). The tax compliance literature might similarly benefit from efforts to use a nonlinear concept of time when describing anticipatory systems. For instance, future events such as a budget decision or the announcement of a tax amnesty can determine current behavioral responses. Hence, Vrobel (2013) explains that to Edmund Husserl, "the Now was not a point-like 
cut between the future and the past, but had extension, as it contained past, present, and future structure" (p. 93).

The tax compliance literature does in fact show that human values shape tax compliance (Torgler and Schneider 2009) and identifies certain factors that may shape those values (Torgler 2007). Our understanding remains limited, however, on the extent to which the increasing mismatch between the rates of biological and cultural evolution holds implications for tax compliance. The literature could thus benefit from integrating knowledge generated by research into the evolution of cooperation and the emergence of social norms. Responsibility or blame, for example, are required for human society to work (Ehrlich 2000), yet these concepts in turn require an understanding of biological and cultural evolution. ${ }^{4}$ That is, as Ehrlich (2000) points out, the capacity to develop ethics, morals, and norms is a product of biological evolution, while the actual choice is mostly a result of cultural evolution. Moreover, although capacity is a product of biological evolution, the answer to what we should do is not: people in different societies have different ethical codes of what is perceived as fairness, obligation, or duty. Ehrlich (2000) thus suggests that deriving policy implications requires a broad understanding of cultural macroevolution (the extrinsic factors of culture) and cultural microevolution, the internal dynamics of societies.

If culture change adapts and diversifies over time and becomes increasingly complex, then biological models and a novel mathematical formalism that allows integration of multiple interacting elements become increasingly important. Quantum models, for instance, are flexible enough to define variables and spaces with respect to a specific context (Gabora et al. 2013). Hence, tax compliance researchers wishing to represent taxpayers (individual and firms), the tax administration, the government, and tax practitioners as biologically active components that are learning and adapting to an uncertain environment might benefit from taking a closer look at developments in biomathics. Using such a dynamic framework is particularly important given the current trend in the tax compliance literature of moving from individual tax compliance to firm tax compliance and from tax evasion to tax avoidance. The tax compliance research agenda has always been "real world" driven, so a more

\footnotetext{
${ }^{4}$ For an excellent discussion on the cultural evolution, see Mesoudi (2011).
} 
globalized world increases the importance of understanding which factors influence tax avoidance and what type of policies can be introduced to handle such issues.

Nevertheless, it still may be the case that, despite mathematical formalism's ability to describe agent-based models (Loembruni and Richiardi 2005), the relevant phenomena have no adequate mathematical representations. If so, simulations can be particularly valuable for throwing light on and predicting system behavior, especially when there is limited information about the rules that govern such behavior (Simon 1996b). Prinz (2014), in his excellent discussion of the importance of simulations in the tax compliance field, emphasizes their ability to link the world of ideas with the world of facts (p. 8). Therefore, in addition to proposing a useful typology (evolutionary, network, or econophysics) and describing the corresponding interactions and dynamics (p. 9), he carefully delineates the strengths and limitations of simulations in the tax compliance context. In particular, he emphasizes that the results from current simulation models imply a failure to detect complexity and emergence in tax compliance and evasion. This failure raises the question of whether better elaboration of other system elements and their interaction would yield more accurate results; for example, including the tax practitioners that are seemingly excluded in most current agent-based models or opening the black box of decision processes within a firm.

Prinz (2014) also, however, visualizes the trade-off between generality of results and complicity of simulations, which brings to mind the following comment from John von Neumann: "With four parameters I can fit an elephant and with five I can make him wiggle his trunk" (cited in Helbing 2012, p. 6). The advantage of simple models is that, by guiding thinking and providing intuition as to what happens when system changes occur, they allow a better understanding of the social mechanisms at work (Helbing 2012). In this regard, Einstein's (1934) suggestion that a model be "as simple as possible, but not simpler" may be useful: "It can scarcely be denied that the supreme goal of all theory is to make the irreducible basic elements as simple and as few as possible without having to surrender the adequate representation of a single datum of experience" (p. 165). Bloomquist (2006, p. 422) acknowledges another trade-off in the tax compliance literature between including as many empirically known relations as possible without using so many elements that they substantially degrade the model performance. In a more recent contribution, Helbing (2012) provides detailed suggestions on how to apply agent-based models that could interest 
researchers who are planning in examining compliance behavior in firms (small and large) that are active locally, nationally, or internationally. Similarly, Bloomquist's (2010) provides an implementation of an evolutionary coordination game to study small businesses.

For obvious reasons, then, agent-based modeling has received increased attention in the tax compliance literature, which identifies a large set of different factors that shape tax compliance. The relevant variables and parameters, however, are hard to measure (e.g., tax evasion), and empirical studies are hampered by limited data availability or inherent biases resulting from difficulty obtaining tax administration cooperation. Likewise, even though the interactions between all the decision makers are relatively strong and continuous over time, taxpayers can have different motivation structures (see, e.g., Torgler 2003) or types (Mittone and Patelli 2000), while the rules of the game (tax reforms) or current political processes can also change. Agent-based models, however, are valuable in that they permit observation of macro outcomes (e.g., at the societal level) based on a microfoundation of human nature and the surrounding influences. As Epstein (1999), a leading researcher in agent-based modeling, puts it, "because the individual is multidimensional, so is the society" (p. 47). Agent-based models thus have the capacity to introduce such concepts as social customs, occupational choices, subject beliefs, (changeable) agent characteristics, social networks, and public expenditures (see, e.g., Korobow et al. 2007, Andrei et al. 2014, Hashimzade et al. 2014, Pellizzari and Rizzi 2014).

In the end, it may be safe to say that tax compliance, with its real world implications, is a child of empirical science. The final test, as Simon (1996a) admits in his autobiography, is a match between theory and data rather than mathematical elegance or a priori plausibility: "I certainly learned that lesson" somewhere, ultimately overcoming my innate Platonism and armoring myself against the aesthetic lures of neoclassical economics, so responsive to mathematical elegance and so indifferent to data" (p. 53).

\section{GENETICS AND ENVIRONMENT}

\footnotetext{
${ }^{5}$ This conclusion emerged when he was a student at Chicago attending Henry Schultz's econometrics class.
} 
One dominant discussion point between social science and biology is the interaction between genes and culture, two factors of which biologists are well aware. Wilson (1998), for example, writes that "we know that virtually all of human behavior is transmitted by culture. We also know that biology has an important effect on the origin of culture and its transmission. The question is how biology and culture interact, and in particular how they interact across all societies to create the commonalities of human nature" (p. 137). As a result, there is a growing interest in exploring the complex relations between genetic and environmental influences in economics - particularly in social dilemma situations - by using laboratory experiments to gain a better understanding and a biological microfoundation. Without doubt, the inevitable, inexpensive, broad-based availability of genotypic information will enhance social scientists' interest in studying individual genetic constitutions (Benjamin et al. 2012). For example, a new field of genoeconomics is already emerging that offers several advantages: advancements in measuring genotypes' direct and exogenous measures of preferences and abilities; the ability to learn about the biological mechanisms of human behavior with the aim of providing a better foundation, which also allows identification of genetic differences that predict heterogeneity in behavior; and the use of genetic markers as control or instrumental variables (Benjamin et al. 2012). Similarly, Algan and Cahuc (2010) explore the causal relation between interpersonal trust and economic growth by using the trust levels inherited by U.S. immigrants and their descendants to create a time-variant measure of trust level that alleviates the problem of reverse causality by assuming a stable transmission of values from generation to generation.

Most extant studies in the area of genoeconomics, however, are candidate gene studies (Benjamin 2012) that raise their own methodological issue: whether single candidates are dominant enough to describe or predict human behavior. The most common method for exploring heritability is the twin study; for example, comparing pairs of monozygotic or dizygotic twin pairs reared together or apart and then comparing the data from both of these to variability in the same trait among nontwinned biological and adopted siblings. Monozygotic twins reared apart (being essentially identical genetically but reared in different cultural environments) provide additional controls for the influence of genes and environment on behavioral responses. Dizygotic twins reared together, on the other hand, test the effect of different genetic constitutions in the same environment. Recognizing such important 
differences, however, runs contrary to the practices of current economic research, most of which assumes that the effect of genetic transmission is sufficiently small to be safely removed from the equation. Yet one recent study using behavioral genetic techniques shows that genetic differences explain around $20 \%$ of individual variations in giving and risk-taking behavior (Cesarini et al. 2009). Nevertheless, such estimates of heritability could be biased toward zero because of measurement errors (Benjamin et al. 2012).

Research with twins is also problematic: environmental factors are highly complex, and monozygotic twins reared together constantly have different experiences that can substantially impact their decision making processes. Genes and culture are thus inseverably linked, a "tortuous" linkage in which "genes prescribe epigenetic rules, which are the neural pathways and regularities in cognitive development by which the individual mind assembles itself. The mind grows from birth to death by absorbing parts of the existing culture available to it, with selections guided through epigenetic rules inherited by the individual brain" (Wilson 1998, p. 138). Genoeconomic studies suffer from other weaknesses (Benjamin et al. 2012); for example, most research designs detect only correlations, and there are common confounding factors, such as a correlation between an individual's genotype and the parents' genotypes, which are in turn correlated with the individual's family environment (pp. 644-646). Hence, when using genes as instrumental variables, the causal effect must be thoroughly understood in order to rule out alternative pathways. There also remains the problem of finding sufficient predictive power from a genetic marker: genetic associations in social sciences studies are often underpowered-that is, they have too few observations for an effect to be detected.

\section{DEMOGRAPHY: AGE AND GENDER}

One stable and significant finding in the tax compliance literature is that age is positively correlated with tax morale (see, e.g., Torgler 2007), a finding not unique to this research stream but also observable in corruption studies (Torgler and Valev 2006) and the most widely accepted fact in the crime literature (Hirschi and Gottfredson 2000). In discussing this effect, Gottfredson and Hirschi (1990) differentiate between desistance theory, which links the results to other age-related factors (e.g., change in social position or status, sensitivity to risk, exposure to anti- 
criminal institutions) and age theory, which argues that the aging of the organism itself has an impact. They suggest that the evidence to date provides more support for age theory, but there is limited understanding as to why this is the case. For example, in the Cambridge Handbook of Age and Ageing (Johnson 2005), the topic of age and compliance or crime does not appear at all.

Understanding how age is linked to cooperative behavior is becoming increasingly important as society ages (List 2004). However, although experimental evidence from the laboratory using nonstudent participants could provide important insights into how age affects cooperation in various environments, many laboratory experiments to date still use student subjects and so throw no light on the age-cooperation link. Longitudinal studies that follow individuals over many years could also offer crucial insights into cooperative behavior and cooperative attitudes over time, while surveys and repeated laboratory experiments conducted with the same participants over a long period could provide important information on how age influences cooperation and willingness to pay taxes. The literature on the biology and psychology of human aging could also make important contributions in that having a better biological foundation for cooperative behavior is crucial to understanding how and why the aging of an organism could itself drive human cooperation and tax morale.

Similarly, there is strong evidence that women are more compliant and have higher tax morale than men (e.g., Torgler 2007, Torgler and Valev 2010). Such results hold even when opportunity is controlled for (Torgler and Valev 2010) or in laboratory experiments in which both genders have the same opportunities and conditions for tax evasion. Again, two theories have been put forward to explain these gender differences: the opportunity for noncompliance and self-control (see Gottfredson and Hirschi 1990, Zager 1994, and Torgler and Valev for detailed discussions), although there are indications that opportunity cannot explain the gender gap. Hence, a better understanding of gender differences is needed. One approach is that taken in Mealey's (2000) work on sex differences, which mentions neither compliance nor crime. Instead, the discussion on cooperation focuses on cooperative breeding linked to the quality of parental care when rearing offspring is demanding (e.g., humans) or the environment harsh (e.g., high levels of predation risk), contexts in which child-rearing requires caregiving assistance from nonreproductive helpers (e.g., offspring from a previous breeding episode). 


\section{NEUROBIOLOGY}

\section{PHYSIOLOGY}

The relatively recent discipline of neuroscience is reshaping the scientific landscape of social or behavioral sciences, especially now that technical advances allow the integration of neuroscientific principles into laboratory experiments. Taking into account that tax compliance experiments are quite complex (as opposed to an ultimatum, or in particular, a dictator game), nonintrusive tools such as skin conductance responses (SCR) or heart rate variability (HRV) measures provide interesting tools (physiological measures) for exploring neurobiology's relation with tax compliance. In particular, the tax compliance literature can benefit from a good understanding of the role played by emotions, which drive human attention and have a powerful effect on the decision process that should not be underestimated (Simon 1983). Specifically, emotions modify the neural activities that animate and focus mental activities, thereby providing stimulus and guidance and causing the selection of certain streams of information over others (Wilson 1998). The large prefrontal and limbic regions, for example, allow us to entertain various options, including whether or not to engage in tax evasion (plan) and whether the chances of getting caught and/or the possible outcomes offset the risk, all key predictive brain functions that promote survival and guarantee well-being by allowing us to anticipate (social) trouble or pain (Churchland 2011).

Yet what exactly does an instrument like HRV measure? This particular method, by recording information on activity in two major parts of the autonomic nervous system (ANS), the sympathetic and parasympathetic systems (see Dulleck et al. 2011, 2012, 2013), measures the body's physical reactions to stressors and throws light on the balance between sympathetic (fight and flight) and vagal (rest and relax) activity. Because the heart rate oscillations generated by these two autonomic system branches occur at different speeds or frequencies (Appelhans and Luecken 2006), the measure also identifies the extent of both activities. Because individuals react to stress with either increased sympathetic and/or decreased parasympathetic activity (Berntson et al. 1994), several studies have used the ratio of activity in the low frequency band to that in the high frequency band (i.e., the LF/HF ratio) as an index of sympathovagal balance (Appelhans and Luecken 2006). This latter serves as a useful index of regulated emotional responding (i.e., the "cardiac signature" of emotions). 
To my knowledge, however, only two extant studies in the tax compliance literature use physiological measurements, with inconclusive results. Coricelli et al. (2010) find that SCR is correlated with self-reported emotional arousal and hedonic valence, and that an increased SCR measured before a decision is made (higher anticipated and anticipatory emotional arousal) is linked with a higher likelihood of evading taxes and more tax evasion. Dulleck et al. (2012), on the other hand, conduct a simple analysis that seemingly confirms Erard and Feinstein's (1994) proposition that the mere intention of a false declaration generates anxiety, guilt, or a reduction in the taxpayer's self-image or self-esteem (manifested as physiological discomfort, psychic stress, dissonance, and anticipated uneasiness at breaking social norms). These negative feelings in turn reduce the utility of tax evasion and thus its likelihood. The concept of pain and emotions, therefore, is at the center of attention. Modification in the situation leads to emotional responses and to the motivation to correct actions in a way that reduces them. Churchland (2011) offers an interesting commentary on this aspect:

Biological evolution does not achieve adaptations by designing a whole new mechanism from scratch, but modifies what is already in place, little bit by little bit. Social emotions, values, and behavior are not the result of a wholly new engineering plan, but rather, an adaptation of existing arrangements and mechanisms that are intimately linked with the self-preserving circuitry for fighting, freezing, and flight, on the one hand, and for rest and digest, on the other. (p. 46)

It is the prefrontal and limbic regions, therefore, that are responsible for entertaining the possibility of future pain and for evaluating plans that deal with it, while pain and fear serve as survival signals that demonstrate the necessity for corrective behavior (Churchland 2011, p. 28). Pain thus serves as a homeostatic emotion that reflects an adverse condition in the body, which then requires a behavioral reaction (Craig 2003).

The results from Coricelli et al. (2010), however, are not consistent with the idea that merely intending to evade taxes induces negative feelings like guilt, reducing the utility of tax evasion and the likelihood or degree of tax evasion. Yet they do provide additional interesting insights. First, they observe that a higher fine is related to negative feelings, maybe because of regret or anger. Learning that their picture is going to be disseminated to other experimental participants is also correlated with more negative feelings, perhaps out of shame. Not being audited, on the other hand, 
generates positive feelings, possibly related to relief and the joy of receiving higher earnings.

Such mixed results from these two studies imply the need for intensified efforts in this research area; for instance, using post-experimental questionnaires might improve understanding of what is happening. Also unclear are the resulting policy implications, meaning that a better understanding of psychic costs and their triggers could be important for such issues as tax system fairness, tax morale, the exchange relationship between taxpayers and the tax administration, quality of governance, and cultural attitudes. Admittedly, some evidence is already available at the attitudinal level; however, at the behavioral level little is known (Dulleck et al. 2012).

Tax compliance research might also benefit from exploring the neuroanatomical basis of moral sentiments, which provides evidence of brain activation patterns for morally relevant versus irrelevant conditions (Zahn et al. 2013). Recent research exploring specific moral sentiments such as guilt or shame might also make interesting contributions. Because certain routines in the tax filing or tax auditing process may lead to habitual system activation, the tax compliance literature might also benefit from better understanding habitual systems and goal-directed control systems, which are computationally more sophisticated (Fehr and Rangel 2011).

It might also be interesting to explore the value of low cost settings; for example, oxytocin, an ancient peptide released naturally in the hypothalamus and diffused widely to other subcortical areas has been shown to be associated with raising both trust and the threshold for tolerating others (for an overview, see Zak 2012). Oxytocin can be administered using a nasal spray without subjects being aware of any shifts in their conscious attitudes. Here again, however, we are confronted with such issues as whether the effect would be sufficiently positive, and if so, would it actually be a good idea to enforce compliance that way. Although trust (in particular, vertical trust) is highly relevant to (understanding) tax compliance, a high level of trust is not always good. If the government performs poorly, for example, tax evasion is a sign of dissatisfaction, which may induce formal or informal institutional changes.

\section{HUMAN DRIVES}

Some behavioral patterns and biases can have a biological evolutionary origin that helps increase the chances of fitness; hence, Lawrence and Nohria (2002) argue that 
human motives begin as subconscious drives that only manifest as conscious emotions at a later stage. Such human drives are located in the limbic region of the brain, which is closely wired to the prefrontal cortex (conscious level). They can be classified as follows (Lawrence and Nohria 2002): (i) the drive to acquire, which leads to caring for relative status that affects happiness (Clark et al. 2003), performance (Frey et al. 2013), or social capital (Fischer and Torgler 2013); (ii) the drive to bond (care, trust, compassion, fairness, loyalty), which allows cooperation with the benefit of increasing group fitness; (iii) the drive to learn, displaying emotions of inquisitiveness, wonder, and curiosity, as well as a need for competence, growth, achievement, mastery, creativity, and efficacy; and (iv) the drive to defend. Each of these drives has genetically evolved in humans to act as a set of decision guides that increase inclusive fitness: "These drives serve to energize and partially steer human reasoning and decision making (cognition), perceiving (the senses), remembering (representation) and acting (skills sets and motor centers) in individuals" (Lawrence and Nohria 2002, pp. 49-50). A closer understanding of human drives might also provide better avenues for understanding human nature and when and under which type of circumstances compliance or noncompliance emerges. Deriving appropriate proxies for such drives would allow their importance at the individual level to be tested both experimentally and with cross-sectional or longitudinal survey data. Firm level data, in particular, would be interesting to analyze.

\section{CONCLUSIONS}

The aim of this short piece was not to preach that biology should be the dominant force that allows us to bring all the different disciplines together for a fuller understanding of tax compliance. Rather, based on limited understanding, I have made broad suggestions about what sort of biological knowledge might be usefully introduced into the field of tax compliance. Continuing preoccupation with the topic could help structure the key issues in a better manner, and researchers with some understanding of tax compliance but a far more extensive background in biology could offer valuable additional insights. Rosser (2006, 2008), for example, provides an insightful discussion on econophysics that identifies two key problems in linking the two fields: first, some economists complain that econophysicists are not properly 
aware of what they do (Rosser 2006) and second, it remains unclear who really preceded whom disciplinarily (Rosser 2008). Such criticism could be reduced through a greater degree of collaboration between economists and econophysicists (Rosser 2008).

Analogously, a lack of awareness about biology might be seen as a key criticism of this present paper. My primary purpose, however, is not to support my contentions with an extensive overview of tax compliance research but rather to offer an avenue through which to encourage a constant rethinking, in the spirit of Herbert Simon, of disciplinary loyalty. Augier and March (2004), for example, recall the following conversational comment from Simon: "If you see any one of these disciplines dominate you, you join the opposition and you fight it for a while" (cited on p. 4). I see this reaction as a refreshing way to avoid being trapped in a "cognitive prison" or to avoid falling in love with one's own constructions, even though at times it may feel like swimming constantly in deep and murky waters. Moreover, digging ever deeper with energy and resolution into the same old hole, while it may be important, does not reflect the heterogeneity of the scientific community. Rather, in a wonderfully crafted article in the American Economist, Dixit (1994) uses a runner's metaphor to dispense the following advice:

Discover your best “distance." Some people are good sprinters in research. They can very quickly spot and make a neat point; they do this frequently, and in many different areas and issues. Hal Varian and Barry Nalebuff are two of the best sprinters I know. In the same metaphor, others are middle-distance runners. In fact most economists are at some point in this broad category. A few, for example Robert Lucas and James Mirrlees, are marathoners; they run only a small number of races, but those are epics, and they get the most (and fully deserved) awe and respect. In contrast, the profession seems to undervalue sprinters. But each kind of work has its own value, and the different types are complements in the overall scheme of things. Progress of the subject as a whole is a relay race, where different stretches are of different lengths and are optimally run by different people. Find out where your comparative advantage lies. (p. 12)

In general, compliance can be seen as a product of biology, environment, and history (Wilson 1998) because, as Morin (2001) emphasizes, a "human being is a biological, psychological, social, emotional, rational being" (p. 31). Yet to date biology has received only limited attention in the tax compliance literature, so it is worth exploring what we can learn from this discipline. I personally share the view of 
many scientists that there has never been a better time for interdisciplinary collaboration and that much of the important research action in the next few decades will take place in the interdisciplinary borderlands. Biology and social science can be seen as siblings in that both are more complex than physics. The great challenge still lies in finding a common language or at least being literate enough in the various languages to bridge the different disciplines in the exemplary fashion achieved by Herbert Simon. Reaching this goal obviously requires much investment, although the transaction cost of such endeavor today are greatly reduced by technological advances like access to articles through Google Scholar and electronic linking to the university library. Once territorial lines are less visible or fall apart, therefore, exciting unexplored terrains will await those who are able and willing to journey into them. As Weinberg (2012) so aptly puts it, “no one knows everything, and you don't have to ... [rather, you] should aim for the rough water ... [and the] messes - that's where the action is" (pp. 63-64).

\section{REFERENCES}

Andrei, A. L., K. Comer, and M. Koehler (2014). An Agent-Based Model of Network Effects on Tax Compliance. Journal of Economic Psychology. 40: 119-133.

Andreoni, J., B. Erard, and J. Feinstein (1998). Tax Compliance, Journal of Economic Literature. 36: 818-860.

Alchian, A. A. (1950). Uncertainty, Evolution, and Economic Theory, Journal of Political Economy. 58: 211-221.

Algan, Y. and P. Cahuc (2010). Inherited Trust and Growth, American Economic Review. 100: 2060-2092.

Alm, James (1998). Tax Compliance and Tax Administration, Andrew Young School of Policy Studies, Georgia State University (revised version published in: W. Bartley Hildreth and J. A Richardso (eds.) (1999), Handbook on Taxation. New York: Marcel Dekker, pp. 741-768).

Alm, J., J. Martinez-Vazquez, and B. Torgler (eds.) (2010). Developing Frameworks for Explaining Tax Compliance. London: Routledge.

Appelhans, B. M. and L. J. Luecken (2006). Heart Rate Variability as an Index of Regulated Emotional Responding, Review of General Psychology. 10: 229-240.

Augier, M. and J. G. March (eds.) (2004). Models of a Man: Essays in Memory of Herbert A. Simon, pp. 433-449. Cambridge, MA: MIT Press, pp. 433-449.

Becker, G. S. (1976). Altruism, Egoism, and Genetic Fitness: Economics and Sociobiology, Journal of Economic Literature. 14: 817-826.

Benjamin, D. J., D. Cesarini, C. F. Chabris, E. L. Glaeser, D. I. Laibson, V. Guðnason, T. B. Harris, L. J. Launer, S. Purcell, A. V. Smith, M. Johannesson, P. K. E. Magnusson, J. P. Beauchamp, N. A. Christakis, C. S. Atwood, B. Hebert, J. Freese, R. M. Hauser, T. 
S. Hauser, A. Grankvist, C. M. Hultman, and P. Lichtenstein (2012). The Promises and Pitfalls of Genoeconomics. 4: 27-662.

Berntson, G. G., Cacioppo, J. T., Binkley, P. F., Uchino, B. N., Quigley, K. S., and Fieldstone, A. (1994). Autonomic cardiac control. III. Psychological stress and cardiac response in autonomic space as revealed by pharmacological blockades. Psychophysiology. 31: 599-608.

Bloomquist, K. M. (2006). A Comparison of Agent-Based Models of Income Tax Evasion. Social Science Computer Review. 24: 411-425.

Bloomquist, K. M. (2010). Tax Compliance as an Evolutionary Coordination Game: An Agent-Based Approach, Public Finance Review. 39: 25-49.

Bowles, S. and H. Gintis (2011). A Cooperative Species: Human Reciprocity and Its Evolution. Princeton: Princeton University Press.

Braithwaite, V. (2002). Taxing Democracy. Aldershot: Asgate

Breit, W. and B. T. Hirsch (2004). Lives of the Laureates. Cambridge Mass.: The MIT Press.

Cazalis, R. (2013). The Organism and Its Double: An Approach to the Individual, Progress in Biophysics and Molecular Biology. 113: 60-66.

Cesarini, D., C. T. Dawes, M. Johannesson, P. Lichtenstein, and B. Wallace (2009). Genetic Variation in Preferences for Giving and Risk Taking, Quarterly Journal of Economics. 124: 809-842.

Churchland, P. S. (2011). Braintrust: What Neuroscience Tells Us About Morality. Princeton: Princeton University Press.

Clark, A. E., P. Frijters, and M. A. Shields (2008). Relative Income, Happiness, and Utility: An Explanation for the Easterlin Paradox and Other Puzzles, Journal of Economic Literature. 46: 95-144.

Coricelli, G., M. Joffily, C. Montmarquette, and M. C. Villeval (2010). Cheating, Emotions, and Rationality: An Experiment on Tax Evasion 13, Experimental Economics. 13: 226247.

Corning, P. A. (2005). Holistic Darwinism: Synergy, Cybernetics, and the Bioeconomics of Evolution. Chicago: Chicago University Press.

Craig, A. D. (2003). A New View of Pain as a Homeostatic Emotion, TRENDS in Neurosciences. 26: 303-307.

De Soto, H. (2000). The Mystery of Capital: Why Capitalism Triumphs in the West and Fails Everywhere Else. New York: Basic Books.

Dixit, A. (1994). My System of Work (Not!), American Economist. 38: 10-16.

Dulleck, U., A. Ristl, M. Schaffner, and B. Torgler (2011). Heart Rate Variability, the Autonomous Nervous System, and Neuroeconomic Experiments, Journal of Neuroscience, Psychology, and Economics. 4: 117-124.

Dulleck, U., J. Fooken, C. Newton, A. Ristl, M. Schaffner, and B. Torgler (2012). Tax Compliance and Psychic Costs: Behavioral Experimental Evidence Using a Physiological Marker, QuBE Working Papers 001, QUT Business School.

Dulleck, U., M. Schaffner and B. Torgler (2013). Heartbeat and Economic Decisions: Observing Mental Stress among Proposers and Responders in the Ultimatum Bargaining Game, QuBE Working Papers 003, QUT Business School.

Ehrlich, P. R. (2000). Human Natures: Genes, Cultures, and the Human Prospects. London: Penguin Books. 
Einstein, A. (1934). On the Method of Theoretical Physics. Philosophy of Science. 1: 163169.

Epstein, J. M. (1999). Agent-Based Computational Models and Generative Social Science, Complexity. 4: 41-60.

Erard, B. and J. Feinstein (1994). The Role of Moral Sentiments and Audit Perceptions in Tax Compliance. Public Finance. 49: 70-89.

Rosser, J. B., Jr., 2008, "Debating the role of econophysics," Nonlinear Dyn., Psychol., Life Sci. 12, 311-323.

List, J. A. (2004). Young, Selfish and Male: Field Evidence of Social Preferences, Economic Journal. 114: 121-149.

Fehr, E., and A. Rangel (2011). Neuroeconomic Foundations of Economic Choice-Recent Advances, Journal of Economic Perspectives. 25: 3-30.

Feynman, R. P. (1999). The Pleasure of Finding Things Out. The Short Works of Richard P. Feynman. New York: Basic Books.

Fischer, J. and B. Torgler (2013). Social Capital and Relative Income Concerns: Evidence from 26 Countries, Economic Inquiry. 51: 1542-1565

Frech, H. E., III (1978). Altruism, Malice and Public Goods: Does Altruism Pay?, Journal of Social Biological Structure. 1: 181-185.

Frey, B. S. and B. Torgler (2007). Tax Morale and Conditional Cooperation, Journal of Comparative Economics. 35: 136-159.

Frey, B. S., M. Schaffner, S. L. Schmidt, and B. Torgler (2013). Do Employees Care about their Relative Income Position? Behavioral Evidence Focusing on Performance in Professional Team Sports, Social Science Quarterly. 94: 912-932.

Gabora, L., E. O. Scott, and S. Kauffman (2013). A Quantum Model of Exaptation: Incorporating Potentiality Into Evolutionary Theory, Progress in Biophysics and Molecular Biology. 113: 108-116.

Haldane, J. B. S. (2009). What I Require From Life: Writings on Science and Life from J. B. S.Haldane (edited by K. Dronamraju). Oxford: Oxford University Press.

Helbing, D. (ed.). (2012). Social Self-Organization: Agent-Based Simulations and Experiments to Study Emergent Social Behavior. Heiderberg: Springer

Hirschi, T. and M. R. Gottfredson (eds.) (1994). The Generality of Deviance. New Brunswick: Transaction Publishers.

Hashimzade, N., G. D. Myles, F. Page, and M. D. Rablen (2014). Social Networks and Occupational Choice: The Endogenous Formation of Attitudes and Beliefs about Tax Compliance, Journal of Economic Psychology. 40: 134-146.

Hirschi, T. and M. R. Gottfredson (2000). Age and the Explanation of Crime, in: R. D. Crutchfield, G. S. Bridges, J. G. Weis and C. Kubrin (eds.), Crime Readings. Thousand Oaks: Pine Forge Press: 138-142.

Hirshleifer, J. (1977). Economics from a Biological Viewpoint, Journal of Law and Economics. 20: 1-52.

Johansson, F. (2004). The Medici Effect: Breakthrough Insights at the Intersection of Ideas, Concepts, and Culture. Boston: Harvard Business School Press.

Johnson, M. L. (ed.) (2005). The Cambridge Handbook of Age and Ageing. Cambridge: Cambridge University Press. 
Karier, T. (2010). Intellectual Capital: Forty Years of the Nobel Prize in Economics. Cambridge: Cambridge University Press.

Kirchler, E. (2007). The Economic Psychology of Tax Behaviour. Cambridge: Cambridge University Press.

Kitto, K. and R. D. Kortschak (2013). Contextual Models and the Non-Newtonian Paradigm, Progress in Biophysics and Molecular Biology. 113: 97-107.

Korobow, A., C. Johnson, and R. Axtell (2007). An Agent-Based Model of Tax Compliance with Social Networks. 60: 589-610.

Lawrence, P. R. and N. Nohria (2002). Driven: How Human Nature Shapes Our Choices. San Francisco: Jossey-Bass.

Marshall, A. (1890). Principles of Economics. New York: Cosimo Classics.

Matsuno, K. (2013). Making Biological Theory More Down to Earth, Progress in Biophysics and Molecular Biology. 113: 46-56.

Mayr, E. (2004). What Makes Biology Unique. Cambridge: Cambridge University Press.

McGee, R. W. (1996). When Is Tax Evasion Unethical? Working Paper, Policy Analysis No. 11, International Business \& Technical Consultants Inc.

Mealey, L. (2000). Sex Differences: Development and Evolutionary Strategies. San Diego: Academic Press.

Mesoudi, A. (2011). Cultural Evolution: How Darwinian Theory Can Explain Human Culture and Synthesize the Social Sciences. Chicago: Chicago University Press.

Mirowski, P. (1989). More Heat than Light. Economics as Social Physics: Physics as Nature's Economics. Cambridge: Cambridge University Press.

Miller, J. G. (1978). Living Systems. New York: McGraw-Hill, Inc.

Mittone, L. and P. Patelli (2000). Imitative Behavior in Tax Evasion, in: B. Stefansson and F. Luna (eds.), Economic Simulations in Swarm: Agent-Based Modelling and Object Oriented Programming. Amsterdam: Kluwer, pp. 133-158.

Morin, E. (2001). Seven Complex Lessons in Education for the Future. Paris: UNESCO Publishing.

Nelson,R. R. and S. G. Winter (1982). An Evolutionary Theory of Economic Change. Cambridge, Mass.: The Belknap Press of Harvard University Press.

Niehans, J. (1990). A History of Economic Theory: Classic Contributions, 1720-1980. Baltimore: The John Hopkins University Press.

Pellizzari, P. and D. Rizzi (2014). Citizenship and Power in an Agent-Based Model of Tax Compliance with Public Expenditure, Journal of Economic Psychology. 40: 35-48.

Piatti, Marco and Benno Torgler (2011). Comments on William Baumol's Toward A Newer Economics: The Future Lies Ahead!, Economics Bulletin. 31: 1313-1321.

Pickhardt, M. and A. Prinz (2014). Behavioral Dynamics of Tax Evasion - A Survey, Journal of Economic Psychology. 40: 1-19.

Prinz, A. (2004). Simulations in Tax Compliance Research: What Are They Good For?, mimeo.

Robson, A. J. (2001). The Biological Basis of Economic Behavior, Journal of Economic Literature. 39: 11-33.

Rosser, J. B., Jr. (2006). The Nature and Future of Econophysics, in Arnab Chatterjee and Bikas K. Chakrabarti (ed.): Econophysics of Stock and Other Markets. Heidelberg: 
Springer, pp. 225-234.

Rosser, J. B., Jr. (2008). Debating the Role of Econophysics, Nonlinear Dynamics, Psychology \& Life Sciences. 12: 311-323.

Samuelson, P. A. (1952). Economic Theory and Mathematics: An Appraisal, American Economic Review (Papers and Proceedings). 42: 56-66.

Samuelson, P. A. (1977a). Generalizing Fischer's 'Reproductive Value': Linear Differential and Difference Equations of 'Dilute' Biological Systems, Proceedings of the National Academy of Science USA. 74: 5189-5192.

Samuelson, P. A. (1977a). Generalizing Fischer's 'Reproductive Value': Nonlinear, Homogeneous, Biparental Systems, Proceedings of the National Academy of Science USA. 74: 5772-5775.

Samuelson, P. A. (1978a). Generalizing Fischer's 'Reproductive Value': Overlapping and Nonoverlapping Gnerations with Competing Genotypes, Proceedings of the National Academy of Science USA. 75: 4062-4066.

Samuelson, P. A. (1978b). Generalizing Fischer's 'Reproductive Value': 'Incipient' and 'Penultimate' Reproductive-Value Functions When Environment Limits Growth; Linear Approximants for Nonlinear Mendelian Mating Models, Proceedings of the National Academy of Science USA. 75: 6327-6331.

Samuelson, P. A. (1980). Fischer's 'Reproductive Value' as an Economic Specimen in Merton's Zoo, Transactions of the New York Academy of Sciences. 39: 126-142.

Samuelson, P. A. (1983). Foundations of Economic Analysis. Cambridge, Mass.: Harvard University Press.

Samuelson, P. A. (1985). Modes of Thought in Economics and Biology. American Economic Review. 75: 166-172.

Slingerland R. and L. Kump (2011). Mathematical Modeling of Earth's Dynamical Systems: A Primer. Princeton: Princeton University Press.

Simon, H. A. (1990). Invariants of Human Behavior, Annual Review of Psychology. 41:1-19.

Simon, H. A. (1996a). Models of My Life. Cambridge, Mass: The MIT Press.

Simon, H. A. (1996b). The Sciences of the Artificial. Cambridge, Mass: The MIT Press. Simon, H. A. (1983). Reason in Human Affairs. Stanford: Stanford University Press.

Spicer, M. W. (1990). On the Desirability of Tax Evasion: Conventional Versus Constitutional Economic Perspectives, Public Finance. 45: 118-126.

Torgler, B. (2001). Is Tax Evasion Never Justifiable?, Journal of Public Finance and Public Choice. 19: 143-168.

Torgler, B. (2003). Tax Morale, Rule Governed Behaviour and Trust, Constitutional Political Economy. 14: 119-140.

Torgler, B. (2007). Tax Compliance and Tax Morale: A Theoretical and Empirical Analysis. Cheltenham, UK: Edward Elgar.

Torgler, B. and M. Piatti (2013). A Century of American Economic Review: Insights on Critical Factors in Journal Publishing Privot. Palgrave/MacMillan.

Torgler, B. and F. Schneider (2009). The Impact of Tax Morale and Institutional Quality on the Shadow Economy, Journal of Economic Psychology. 30: 228-245.

Torgler, B. and N. T. Valev (2006). Corruption and Age, Journal of Bioeconomics. 8: 133145 . 
Torgler, B. and N. T. Valev (2010). Gender and Public Attitudes Towards Corruption and Tax Evasion, Contemporary Economic Policy. 28: 554-568.

Traxler, C. (2010). Social Norms and Conditional Cooperative Taxpayers, European Journal of Political Economy. 26: 89-103.

Tullock, G. (1978). Altruism, Malice and Public Goods. Journal of Social Biological Structure.1: 3-9.

Vrobel, S. (2013). Measuring the Temporal Extension of the Now, Progress in Biophysics and Molecular Biology. 113: 92-96.

Zager, M. A. (1994). Gender and Crime, in: T. Hirschi and M. R. Gottfredson (eds.), The Generality of Deviance. New Brunswick: Transaction Publishers: 71-80.

Zahn, R., R. de Oliveira-Souza, and J. Moll (2013). Moral Emotions, in: J. Armony and P. Vuilleumier (eds.), Cambridge Handbook of Human Affective Neuroscience. Cambridge: Cambridge University Press, pp. 491-508.

Zak, P. J. (2012). The Moral Molecule: The Source of Love and Prosperity. New York: Dutton.

Zak, P. J. and A. T. Denzau (2001). Economics and the Evolutionary Study of Human Behavior, in: S. A. Peterson and A. Somit (eds.), Evolutionary Approaches in the Behavioral Sciences: Toward a Better Understanding of Human Nature. Research in Biopolitics, Vol. 8. Amsterdam: Elsevier Science, pp. 31-65.

Webber, C. and A. Wildavsky (1986). A History of Taxation and Expenditure in the Western World. New York: Simon and Schuster.

Weinberg, S. (2012). Four Golden Lessons, in: R. D. Smith (ed.), Scientific Work and Creativity: Advice from the Masters. Clearwater: Citizen Scientists League, pp. 63-65.

Wilson, E. O. (1998). Consilience: The Unity of Knowledge. New York: Vintage Books. 